\title{
Burn prevention in the face of global wealth inequality
}

\author{
Gabriel Hundeshagen ${ }^{1 *}$, Paul Wurzer ${ }^{1,2}$, Abigail A. Forbes', Janos Cambiaso-Daniel ${ }^{2}$, Omar Nunez-Lopez², \\ Ludwik K. Branski, ${ }^{1,2}$ and David N. Herndon ${ }^{1}$
}

\begin{abstract}
Background: Burn injuries remain a consistent challenge for providers of medical care worldwide and thus the current focus of medical professionals is on improving treatments and reducing the incidence of burns altogether. We conducted a literature search to summarize worldwide promoted burn prevention strategies.

Methods: A review of the Medline database was conducted using PubMed interface. Abstract screening and full-text analysis of eligible article was performed. Burn prevention strategies were summarized and sorted by origin.

Results: Between 2005 and now, 34 articles regarding burn prevention have been published. Seventy four percent of the articles were published in high income countries, followed by middle income countries with $18 \%$ and low income countries with $9 \%$ of all the manuscripts. The United States published the most articles $(n=17)$, followed by the United Kingdom $(n=5)$, and Iran $(n=3)$.

Conclusions: Although many hardships and barriers need to be overcome, it is more than worthwhile that high income countries should invest a great amount of effort to help low and middle income countries to create strategies to prevent burn injuries, as those burns, which do not occur will always have the best outcome.
\end{abstract}

Keywords: Burns, Awareness, Prevention, Scald, Flame, Electrical

\section{Background}

Burn injuries remain a consistent challenge for providers of medical care worldwide, with approximately 300,000 fatalities and millions of patients affected by long-term consequences of thermal injuries each year. Two general approaches are taken to tackle this problem: improve treatment and reduce the incidence of burns altogether. Means and modalities of burn care and their respective outcomes are continuously improving, resulting for instance in decreased mortality from 6.2 to $3.2 \%$, shortened length of hospitalization from 13 to 8.6 days and increasing survival rates even for most extensive total body surface area (TBSA) burns over the last two decades in the US $[1,2]$.

Keynote lectures at the European Burn Conference in 2015 have brought up the discrepancies in the causes of burns depending on the income of the country. Thus

\footnotetext{
* Correspondence: gabrielhundeshagen@gmail.com

${ }^{1}$ Department of Surgery, University of Texas Medical Branch and Shriners Hospitals for Children — Galveston, 815 Market Street, Galveston, TX 77550, USA

Full list of author information is available at the end of the article
}

tailored burn prevention strategies are required for each geographical location to ensure a reduction of burns. The WHO, American Burn Association and others have designed burn prevention strategies to accomplish the individual needs of burn prevention.

However, there is no general summary of all those prevention strategies which shows similarities and controversies of each approach. We aimed to conduct a brief literature search to summarize currently available burn prevention strategies and show up which countries are developing those.

\section{Methods}

Medical literature was reviewed in order to identify all studies of burn prevention, and burn prevention strategies. A review of the Medline database was conducted using PubMed (accessed 03/01/2016) interface. We limited the search to only articles written in the English language and published between 2005 and now. In addition, the same terms were used for google.com searches to detect further not PubMed listed articles. 
On the PubMed interface, we used the following search terms: ("prevention"[Title] OR "awareness"[Title] AND ("burns"[MeSH Terms] OR "burns"[MeSH Terms] OR "burn" [MeSH Terms] OR "thermal trauma" $[\mathrm{MeSH}$ Terms]).

Abstract screening and when appropriate full-text analysis of eligible article was performed and all burn prevention strategies were summarized in Table 1. Special focus on geographical differences based on the income [3] of the several countries were summarized.

\section{Results}

From 854 identified articles in PubMed, 34 were eligible for full-text analysis (Fig. 1). Most burn prevention

Table 1 Summary of recently published burn prevention strategies

\begin{tabular}{|c|c|c|c|}
\hline Author & Year & Origin & Prevention strategies \\
\hline D’ Cruz et al. & 2015 & Australia & Use of child-resistant packaging and improved parental practices \\
\hline Marcucci et al. & 2010 & Canada & Burn prevention programs for electricians, Safer multimeters with fused leads \\
\hline Wong et al. & 2007 & China & Interactive graphical illustrations on burn prevention to educate elderly, their family and caregivers \\
\hline Unglaub et al. & 2005 & Germany & Water temperature regulation \\
\hline Sarma & 2011 & India & Community seminars and school programs on burn prevention \\
\hline Ahmadi et al. & 2007 & Iran & Community-based prevention programs, Use of videos of victim stories \\
\hline Mohseni et al. & 2011 & Iran & Television Broadcast of special preventive programs \\
\hline Rasouli et al. & 2015 & Iran & Nationwide chemical burn safety education \\
\hline Peleg et al. & 2005 & Israel & Establish centralized prevention school programs \\
\hline Atiyeh et al. & 2009 & Lebanon & $\begin{array}{l}\text { Establish Fire and burn safety education in schools, community awareness programs, } \\
\text { legislation and prevention codes }\end{array}$ \\
\hline Olaitab and Olaitan & 2005 & Niger & Fire and cooking safety, no loose clothing \\
\hline Sadeghi et al. & 2011 & Sweden & Use of safer consumer appliances, Public health education \\
\hline Grivna et al. & 2014 & UAE & Safety education to caregivers, close supervision of young children, occupational safety education \\
\hline Bayne & 2008 & UK & Avoid alcoholic skin prep and use occluding drape to prevent fluid spread when using tourniquet \\
\hline Hodgins et al. & 2011 & UK & Establish burn prevention programs in low and middle income communities \\
\hline Kendrick et al. & 2012 & UK & Use of home safety equipment, Healthcare provider educating patients on burn safety \\
\hline Durand et al. & 2012 & UK & Water temperature regulation \\
\hline Oomman et al. & 2013 & UK & Public awareness and online learning tools via internet videos \\
\hline Alden et al. & 2005 & USA & Burn-injury prevention program for patients and caregiver \\
\hline Klein et al. & 2005 & USA & Public education and public service announcements \\
\hline Cagle et al. & 2006 & USA & Focused prevention programs to include parent workshops and home visits for environment changes \\
\hline Alden et al. & 2006 & USA & $\begin{array}{l}\text { Installation and use of safety devices, Educational guidelines for consumers } \\
\text { of household items }\end{array}$ \\
\hline Forjuoh SN & 2006 & USA & Environmental modifications, parental education, and Kitchen product redesign and safety \\
\hline O'Brien et al. & 2008 & USA & $\begin{array}{l}\text { Educate on potential household hazards and cooking safety, Use of child proof devices, } \\
\text { Burn prevention programs in schools }\end{array}$ \\
\hline Palmieri et al. & 2008 & USA & Change soup packaging, Educate families with multiple children \\
\hline Peck et al. & 2009 & USA & $\begin{array}{l}\text { Prevention education, training to health personnel, engineering changes, enforcement } \\
\text { of legislative protection and environmental modifications }\end{array}$ \\
\hline Leahy et al. & 2012 & USA & Community based, culturally sensitive programs for senior citizens. \\
\hline Lloyd et al. & 2012 & USA & Educate patients and families on burn prevention during well-child visits \\
\hline Rieman et al. & 2012 & USA & Burn prevention education in schools \\
\hline Heard et al. & 2013 & USA & Establish customized and integrated educational school programs \\
\hline Heard et al. & 2013 & USA & Distribute burn prevention coloring books to schools \\
\hline Lehna et al. & 2014 & USA & Educate and train health care providers on burn prevention knowledge \\
\hline Natarajan M & 2014 & USA & Establish burn education campaign for young women and girls, Safer stove fuel option \\
\hline Gamelli et al. & 2015 & USA & Educate caregivers in healthcare settings and establish training programs for daycare workers \\
\hline
\end{tabular}




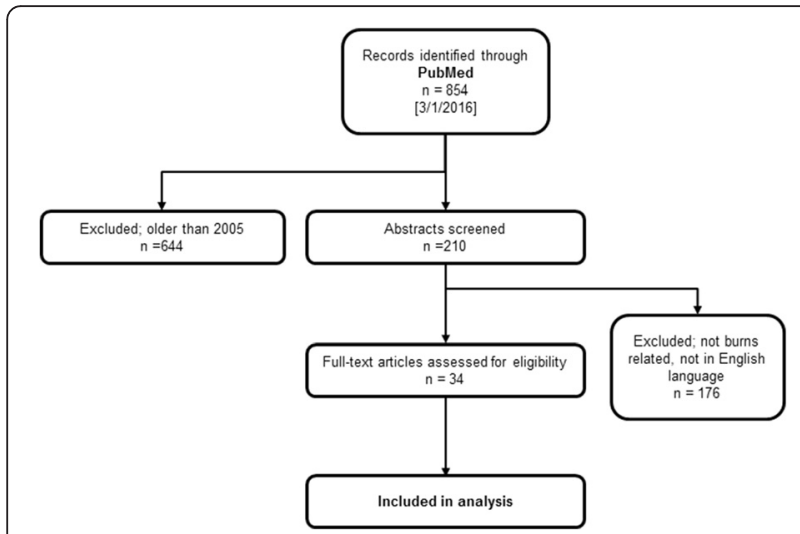

Fig. 1 Flow chart

strategies were published in the United States of America and Canada (50\%), followed by the European Union (21 \%) and the Middle East (18\%, Fig. 2). Asia was the origin of $6 \%$ of the manuscripts, and $3 \%$ came from Africa as well as Australia. $74 \%$ of the articles were published in high income countries. Whereas middle income countries published $18 \%$ and low income countries $9 \%$ of all the manuscripts. The United States was the country with the most articles published $(n=17)$, followed by the United Kingdom $(n=5)$, and Iran $(n=3$, Table 1$)$.

\section{Discussion}

Our study showed that most of the burn prevention strategies were published in high income countries, which did not necessarily mean that they described burn prevention of those countries. A handful of those studies described prevention strategies for Africa and the Middle East. No prevention strategies were published in South America as well as Russia, which both can be graded as middle income countries [3]. Interestingly, all of the published strategies can be found in the strategies developed by the WHO (Table 2). Thus we assume that a general approach to prevent burns in LMIC must be provided high income countries, which have already established low incidences of burns and thus can provide knowledge to LMIC.

Prevention efforts have been accompanying these positive developments for decades: by means of education, changes in engineering, adapting and enforcing protective legislature and environmental modifications, the overall incidence of burn injury could be lowered substantially in the US. Limiting water heater temperatures and installment of smoke detectors are two widespread examples of primary prevention [4]. Furthermore governmental and non-governmental agencies are enhancing secondary prevention through educating the public on how to respond to thermal injury ideally when it does occur. Leaflets, social media PSAs and safety instructions at the workplace are only few examples of undertaken measures [5].

For example this year in February, Shriners Hospitals for Children are launching a year-long campaign entitled "Burn Awareness" [6]. In an educational video for children and adults, two comic characters, Boots and Brewster, are leading children through several rooms in a household to point out dangers and to teach how to avoid them. The video can be downloaded for free. In addition, activity books, which are provided in several languages, focusing on burn prevention and awareness can also be ordered via the Shriners Hospitals for Children homepage.

As encouraging as these accomplishments are, one must be mindful that they have only been achieved for developed high-income countries (HIC) such as the US and most countries of Europe. However, $95 \%$ of annual burn injuries occur in countries of low and middle income (LMIC), where mortality rates are up to 10 times higher than in their high income counterparts [7]. In a joint effort to improve this situation, the World Health Organization (WHO) and the International Society for Burn Injuries (ISBI) launched "A WHO plan for burn

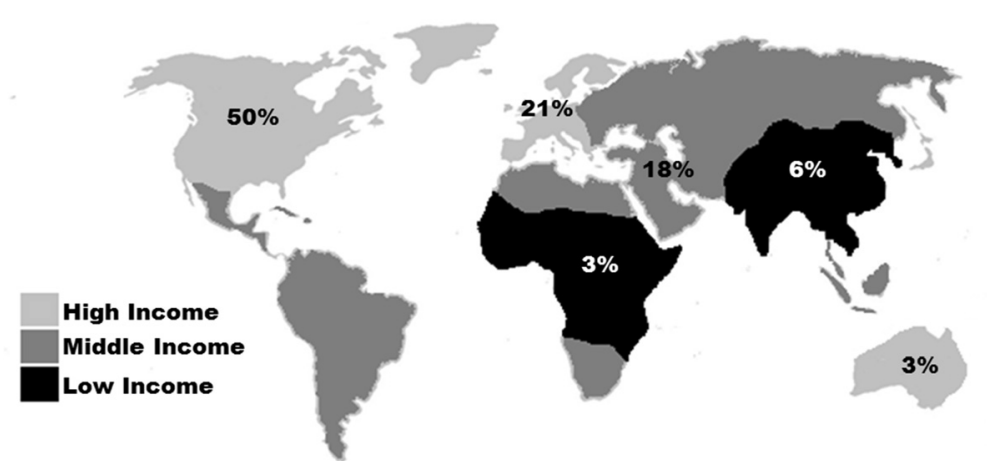

Fig. 2 Map showing the distribution of the income classes and percent of prevention articles published between 2005 and now 
Table 2 Burn preventions strategies adapted from the WHO [10]

\begin{tabular}{|c|c|c|}
\hline Prevention & Background & Solution \\
\hline Fire detection systems and sprinkler & $\begin{array}{l}\text { House fires are still a major cause of burns } \\
\text { and inhalation injuries. }\end{array}$ & $\begin{array}{l}\text { Fire detection devices (based on smoke detection) } \\
\text { and sprinklers should be mandatory for all new buildings. }\end{array}$ \\
\hline $\begin{array}{l}\text { Temperature regulation on } \\
\text { hot water heater }\end{array}$ & $\begin{array}{l}\text { In children, scald burns are more common } \\
\text { than flame burns. }\end{array}$ & $\begin{array}{l}\text { To lower the set temperature of water heaters to roughly } \\
50^{\circ} \mathrm{C}\left(\sim 120^{\circ} \mathrm{F}\right) .\end{array}$ \\
\hline Nonflammable fabrics & $\begin{array}{l}\text { Clothes can easily catch fire, especially from } \\
\text { contact with open fire (cigarettes, candles) } \\
\text { or stoves. }\end{array}$ & $\begin{array}{l}\text { The use of nonflammable sleepwear especially for } \\
\text { children and toddlers. }\end{array}$ \\
\hline Electrical safety & $\begin{array}{l}\text { Electrical burns are the most sever type of } \\
\text { burns and usually result in severe sequelae. }\end{array}$ & $\begin{array}{l}\text { To ensure that electricity is used and delivered safely. } \\
\text { Techniques for safety such as adequate insulation } \\
\text { are necessary. }\end{array}$ \\
\hline Fire-Safe-Cigarettes & $\begin{array}{l}\text { Fire from tobacco products are also a leading } \\
\text { cause for burn injuries worldwide. }\end{array}$ & $\begin{array}{l}\text { Ideally, stop the use of tobacco and smoking would } \\
\text { be the best prevention. However, stopping indoor } \\
\text { smoking is a step forward. }\end{array}$ \\
\hline Safer fireworks & $\begin{array}{l}\text { Burns from fireworks are a problem of both, } \\
\text { high- and middle-income countries. }\end{array}$ & $\begin{array}{l}\text { The purchase and use of fireworks needs to be } \\
\text { more strictly regulated. }\end{array}$ \\
\hline Safer stoves and lamps & $\begin{array}{l}\text { Even nowadays, many households in middle- } \\
\text { and low-income countries use open fires } \\
\text { for daily cooking. }\end{array}$ & $\begin{array}{l}\text { The goal is to create a safer methods for daily cooking } \\
\text { in those countries. New type of stoves and lamps are } \\
\text { part of ongoing developments. }\end{array}$ \\
\hline Combating acid-throwing & $\begin{array}{l}\text { The throwing of acids on faces leading in } \\
\text { severe damage and disfigurement has become } \\
\text { very popular. }\end{array}$ & $\begin{array}{l}\text { Prevent the disposal of acids as well as the prevention } \\
\text { of violence are the main goals to prevent those } \\
\text { chemical burns. }\end{array}$ \\
\hline
\end{tabular}

prevention and care" in 2008, a 10-year prospective program designed to reduce thermal injury risks and standardize fundamental principles of burn treatment in LMIC [7].

Key goals of the program are to raise awareness for burn related problems, influence policies, regulations, legislation and their enforcement and to develop prevention programs and national burn strategies. The potential of preventive measures cannot be overrated in terms of cost-effectiveness, as there has been convincing data from the US which demonstrated manifold savings in health expenditure for every dollar spent on preventive measures [8]. With this in mind, a great deal of WHO's prevention measures for LMIC target the same objectives as in HIC (smoke detectors, hot water temperature regulation, safety regulations for electric wiring, etc.). On the contrary, other risk factors are unique to the conditions in underdeveloped regions such as cooking with open fire, pots on ground level, use of kerosene lamps and easily ignitable loose clothing and thus need to be addressed specifically.

Another important aim of the WHO plan is to improve and standardize treatment for burn injuries. This is not only limited to acute care in specialized hospitals, but also includes educating the public on how to correctly react immediately after a burn occurs. Measures that are already widely taught in HIC through government and non-government agencies, such as immediate cooling, removing all clothing from the burned area and applying dry cloth while avoiding any creams, ointments or home remedies, are supposed to be introduced in
LMIC as well. An encouraging large cohort study was recently published out of Shanghai, where the percentage of patients who had been educated on these effective methods via traditional media, internet or workplace education had a significantly better outcome across all types of burn injuries [9].

The current research has several limitations. The timeframe, 2005 up to now, as well as the use of PubMed only are definitively limitations of the study. We further included articles which have been published in English and thus our calculations regarding the origin of the prevention strategies might have been biased.

Lastly, a key goal of the WHO plan is to collect research data in an organized and comprehensive manner in order to validate the effectiveness of the undertaken efforts, as well as to provide valuable insights for the research community and future improvement of treatment and prevention programs [7].

\section{Conclusions}

Although many hardships and barriers need to be overcome, it is more than worthwhile that high income countries should invest a great amount of effort to help LMIC to create strategies to prevent burn injuries, as those burns, which do not occur will always have the best outcome.

\section{Competing interests}

The authors declare that they have no competing interests.

Authors' contributions

All authors read and approved the final manuscript. 


\section{Author details}

'Department of Surgery, University of Texas Medical Branch and Shriners Hospitals for Children — Galveston, 815 Market Street, Galveston, TX 77550, USA. ${ }^{2}$ Division of Plastic, Aesthetic and Reconstructive Surgery, Department of Surgery, Medical University of Graz, Auenbruggerplatz 29, 8036 Graz, Austria.

Received: 10 February 2016 Accepted: 5 April 2016

\section{Published online: 16 May 2016}

\section{References}

1. American Burn Association. 2015 National Burn Repository [http://www. ameriburn.org/2015NBRAnnualReport.pdf]

2. Miller SF et al. National Burn Repository 2005: a ten-year review. J Burn Care Res. 2006:27(4):411-36.

3. The World Bank Group. Grouping Countries by Their Level of Development [http://www.worldbank.org/depweb/beyond/global/chapter2_2.html]

4. Peck M, Molnar J, Swart D. A global plan for burn prevention and care. Bull World Health Organ. 2009:87(10):802-3.

5. The U.S. Fire Administration. Working for a fire-safe America [www.usfa. fema.gov/citizen/focus]

6. Shriners Hopsitals for Children. Be Burn Aware [www.burnawareness.org]

7. Mock C et al. A WHO plan for burn prevention and care. Geneva: World Health Organization; 2008.

8. Haddix AC et al. Cost effectiveness analysis of a smoke alarm giveaway program in Oklahoma City, Oklahoma. Injury Prevention. 2001;7(4):276-81.

9. Ji SZ et al. Pre-hospital emergency burn management in Shanghai: analysis of 1868 burn patients. Burns. 2012;38(8):1174-80.

10. World Health Organization. Success Stories, Lessons Learned [http://apps. who.int/iris/bitstream/10665/97938/1/9789241501187_eng.pdf]

\section{Submit your next manuscript to BioMed Central} and we will help you at every step:

- We accept pre-submission inquiries

- Our selector tool helps you to find the most relevant journal

- We provide round the clock customer support

- Convenient online submission

- Thorough peer review

- Inclusion in PubMed and all major indexing services

- Maximum visibility for your research

Submit your manuscript at www.biomedcentral.com/submit 